\title{
Aortic symmetry index for symmetric repair
}

Chee-hoon Lee, MD, Ho Jin Kim, MD, and Joon Bum Kim, MD, PhD

\footnotetext{
From the Department of Thoracic and Cardiovascular Surgery, Asan Medical Center, University of Ulsan College of Medicine, Seoul, Republic of Korea.

Disclosures: Authors have nothing to disclose with regard to commercial support.

Received for publication May 23, 2018; revisions received May 23, 2018; accepted for publication May 30, 2018; available ahead of print July 7, 2018.

Address for reprints: Joon Bum Kim, MD, PhD, Department of Thoracic and Cardiovascular Surgery, Asan Medical Center, University of Ulsan College of Medicine, 88, Olympic-ro 43-gil, Songpa-gu, Seoul 05505, Republic of Korea (E-mail: jbkim1975@amc.seoul.kr).

J Thorac Cardiovasc Surg 2018;156:1397-8

$0022-5223 / \$ 36.00$

Copyright (C) 2018 by The American Association for Thoracic Surgery

https://doi.org/10.1016/j.jtcvs.2018.05.106
}

Aortic valve (AV)-sparing root reimplantation (AVSRR) has been established as a reasonable surgical option in treating aortic root aneurysm with or without significant aortic insufficiency (AI). Despite the technical challenges intrinsic to AVSRR, clinical outcomes from several highvolume centers have suggested excellent long-term durability and favorable overall survival relative to composite valve-graft replacement, especially with regard to achieving superior hemodynamics and avoiding lifelong anticoagulation and subsequent complications. ${ }^{1,2}$ Despite these advantages, concerns still exist as to whether the reported excellent outcomes in experienced hands is reproducible by "average" cardiac surgeons. ${ }^{3}$ Although comprehensive understanding and preoperative evaluation of root anatomy are regarded to be indispensable in performing successful AVSRR, ${ }^{3}$ the failure mechanism has been mainly focused on the intraoperative variables, such as height of the coaptation, leaflet integrity, or intraoperative residual AI. In contrast, preoperative indicators to predict postoperative AI have not been well evaluated.

In light of this deficit, Di Franco and colleagues ${ }^{4}$ have published a brief research report in this issue of the Journal in which they investigated whether asymmetric nature of the AV has a predictive value for postoperative AV function by evaluating 67 patients who had tricuspid AV and underwent a classic David I procedure. ${ }^{4}$ Asymmetric nature of the AV was measured with the formula of an aortic symmetry index (ASI), which was grounded by the ratios of intercommissural (IC) triangle. ASI is calculated to be zero for the intercommissural equidistance from each commissure to the other and increases as the ratio of intercommissural distance between each coronary cusp to the other increases (Figure 1). During a mean follow-up of 2.9 years, 5.9\% of patients had development of AI of grade 3 or more. ASI was significantly predictive of postoperative AI, in that patients in whom significant AI developed had higher ASI values than did those without AI. Here, it is important to note that a small difference may have a huge impact on

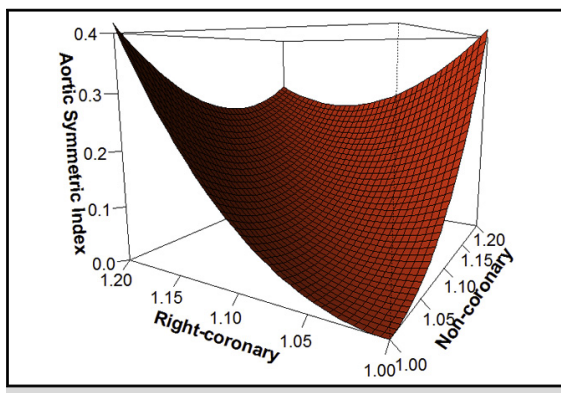

Relationship between intercommissural distance and aortic symmetry index.

Central Message

Aortic symmetry index may be a useful indicator to predict postoperative aortic insufficiency after the David procedure. Its utility is pending the validation from future studies.

See Article page 1393.

late outcome. For instance, more than 10\% discrepancy in the intercommissural distances - which perhaps may be only a 2- to 3-mm difference-results in ASI of 0.1 or greater, which is greater than the average ASI of those without late significant AI (0.09).

Di Franco and colleagues ${ }^{4}$ are to be congratulated on initiating a novel and timely concept of ASI. They handled the issue adequately, and their results are convincing. Notwithstanding, this study did not address several

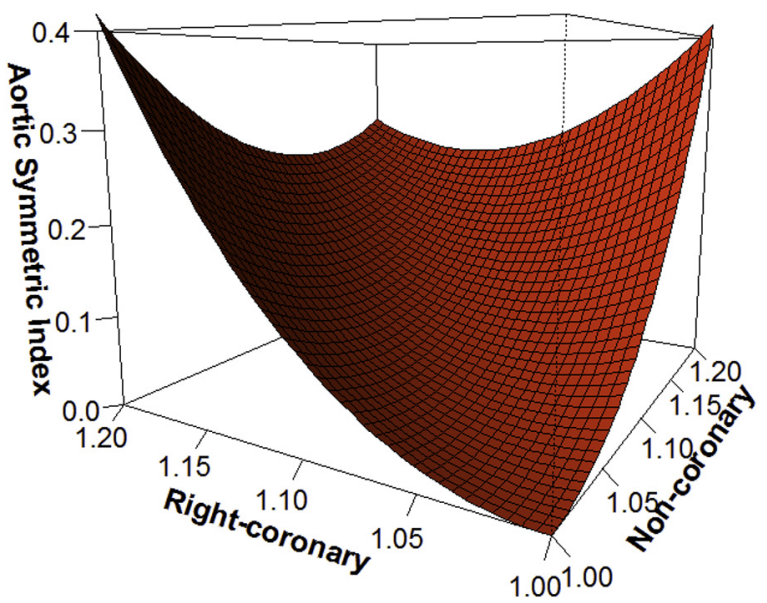

FIGURE 1. Relationship between intercommissural distance and aortic symmetry index. The horizontal axis represents the ratio of the intercommissural distance between each coronary cusp to the left coronary cusp; the vertical axis represents the aortic symmetry index. 
considerations that would have provided more solid grounds. First, because the intercommissural distance was measured by transesophageal echocardiography only, the measurements would better be validated with other imaging studies, such as computed tomography. Second, with asymmetric intercommissural distances manifested by high ASI, it is undoubtedly challenging to achieve good results after AVSRR. Procedural adjustments such as leaflet plication stitch to balance the intercommissural distances can be applied during AVSRR, however, which was not considered in this study.

As argued by Di Franco and colleagues, ${ }^{4}$ the utility of ASI should be validated in future studies with larger data set. We look forward to seeing more widespread sharing of the benefits of AVSRR, with more reliable and reproducible outcomes.

\section{References}

1. Price J, Magruder JT, Young A, Grimm JC, Patel ND, Alejo D, et al. Long-term outcomes of aortic root operations for Marfan syndrome: a comparison of Bentall versus aortic valve-sparing procedures. J Thorac Cardiovasc Surg. 2016;151: 330-6.

2. Ouzounian M, Rao V, Manlhiot C, Abraham N, David C, Feindel CM, et al. Valvesparing root replacement compared with composite valve graft procedures in patients with aortic root dilation. J Am Coll Cardiol. 2016;68:1838-47.

3. David TE. Aortic valve sparing in different aortic valve and aortic root conditions. J Am Coll Cardiol. 2016;68:654-64.

4. Di Franco A, Rong LQ, Munja M, Weinsaft JW, Kim J, Sturla F, et al. Aortic symmetry index: initial validation of a novel preoperative predictor of recurrent aortic insufficiency after valve-sparing aortic root reconstruction. J Thorac Cardiovasc Surg. 2018;156:1393-4. 